\title{
Socioeconomic status and breast cancer incidence: a prospective cohort study
}

Citation for published version (APA):

van Loon, A. J. M., Goldbohm, R. A., \& van den Brandt, P. A. (1994). Socioeconomic status and breast cancer incidence: a prospective cohort study. International Journal of Epidemiology, 23(5), 899-905. https://doi.org/10.1093/ije/23.5.899

Document status and date:

Published: 01/01/1994

DOI:

10.1093/ije/23.5.899

Document Version:

Publisher's PDF, also known as Version of record

\section{Please check the document version of this publication:}

- A submitted manuscript is the version of the article upon submission and before peer-review. There can be important differences between the submitted version and the official published version of record.

People interested in the research are advised to contact the author for the final version of the publication, or visit the DOI to the publisher's website.

- The final author version and the galley proof are versions of the publication after peer review.

- The final published version features the final layout of the paper including the volume, issue and page numbers.

Link to publication

\footnotetext{
General rights rights.

- You may freely distribute the URL identifying the publication in the public portal. please follow below link for the End User Agreement:

www.umlib.nl/taverne-license

Take down policy

If you believe that this document breaches copyright please contact us at:

repository@maastrichtuniversity.nl

providing details and we will investigate your claim.
}

Copyright and moral rights for the publications made accessible in the public portal are retained by the authors and/or other copyright owners and it is a condition of accessing publications that users recognise and abide by the legal requirements associated with these

- Users may download and print one copy of any publication from the public portal for the purpose of private study or research.

- You may not further distribute the material or use it for any profit-making activity or commercial gain

If the publication is distributed under the terms of Article $25 \mathrm{fa}$ of the Dutch Copyright Act, indicated by the "Taverne" license above, 


\title{
Socioeconomic Status and Breast Cancer Incidence: A Prospective Cohort Study
}

\author{
A JEANNE M VAN LOON, ${ }^{\star}$ R ALEXANDRA GOLDBOHM ${ }^{\star}, \dagger$ AND PIET A VAN DEN BRANDT*
}

Van Loon A J M (University of Limburg, Department of Epidemiology, POB 616, 6200 MD Maastricht, The Netherlands), Goldbohm R A and van den Brandt P A. Socioeconomic status and breast cancer incidence: A prospective cohort study. International Journal of Epidemiology 1994; 23: 899-905.

Background. To gain more insight into the relation between socioeconomic status (SES) and breast cancer risk, we have studied that association, before and after adjustment for traditional risk factors for breast cancer, in a prospective cohort study on lifestyle and cancer that started in 1986 in the Netherlands amongst 62573 women aged $55-69$ years. Methods. At baseline, data on SES, diet, reproductive factors and other covariates were collected by means of a self-administered questionnaire. For data-analysis a case-cohort approach was used. After 3.3 years of follow-up, 471 incident cases were available for analysis.

Results. We did not find a higher age-adjusted risk of breast cancer for those with a higher level of education (RR highest/lowest level of education $=0.94,95 \%$ confidence interval $[\mathrm{CI}]: 0.63-1.39$, trend-P=0.15). Although upper whitecollar workers had a slightly higher breast cancer risk than blue-collar workers ( $\mathrm{RR}=1.16,95 \% \mathrm{Cl}: 0.83-1.62$, trend- $P$ $=0.34$ ), women with a profession of higher social standing did not have a higher risk (RR highest/lowest social standing $=0.73,95 \% \mathrm{Cl}: 0.24-2.23$, trend- $P=0.86$ ). Additional adjustment for traditional risk factors did not alter the association between SES and breast cancer risk.

Conclusions. We did not find an association between SES and breast cancer risk. This is not in agreement with studies conducted in other European countries and North America.

Recent epidemiological investigations have indicated a positive relation between breast cancer and socioeconomic status (SES); ${ }^{1-12}$ all studies but one ${ }^{7}$ show positive associations, with relative risks for the highest versus the lowest categories varying from 1.0 to 2.5 . Important risk factors like nulliparity, late age at first birth and late age at menopause $e^{13-15}$ may be (partially) responsible for this positive association because these characteristics are more prevalent among women of higher SES. ${ }^{16}$ In some of the studies on SES and breast cancer, adjustment is made for these reproductive variables. ${ }^{4,6,7,10}$ This led to different results: one study still found significant positive associations between occupational status and breast cancer after adjustment for the covariates mentioned above, but not for education and breast cancer. ${ }^{4}$ In two studies the positive age-adjusted association between SES and breast cancer did not remain significant after adjustment for age, place of residence, parity ${ }^{6}$ and other relevant reproductive variables, body mass index and alcohol use. ${ }^{10}$

\footnotetext{
- University of Limburg, Department of Epidemiology, РОВ 616 , $6200 \mathrm{MD}$ Maastricht, The Netherlands.

${ }^{\dagger}$ TNO-Toxicology and Nutrition Institute, Department of Nutrition, Zeist, The Netherlands.
}

The fourth study did not report positive associations between SES and breast cancer with or without adjustment for known risk factors. ${ }^{7}$ To gain more insight into the relation between SES and breast cancer risk we have studied the association in the Netherlands, in a prospective cohort study on diet, other lifestyle variables and cancer, without and with adjustment for traditional risk. factors for breast cancer.

\section{MATERIALS AND METHODS \\ The Cohort Study}

In September 1986, a prospective cohort study was started in the Netherlands on various lifestyle variables, sociodemographic indicators and cancer risk. The cohort include 58279 men and 62573 women aged 55-69 years at the beginning of the study. Data were collected by means of a self-administered questionnaire. A detailed description of the cohort study design has been reported elsewhere. ${ }^{17}$ For data analysis the case-cohort approach was used in which cases are derived from the entire cohort, while the person-years at risk are estimated from a random sample of 3500 subjects (subcohort). After the baseline exposure 
measurement the subcohort was randomly sampled (1688 men and 1812 women) and it has been followed up biennially for vital status information.

Follow-up for incident cancer has been established by record linkage with all regional cancer registries in the Netherlands and with a national pathology register (PALGA). The method of record linkage has been described previously. ${ }^{18}$ The analysis is restricted to breast cancer incidence from September 1986 to December 1989. In this period, completeness of followup was estimated to be $95 \%$, ${ }^{19}$

After these 3.3 years of follow-up 553 breast cancer cases were detected. We excluded prevalent cancer cases other than skin cancer $(n=67)$ and cases with in situ carcinoma $(n=15)$. Therefore 471 incident cases were available for analysis. Prevalent cancer cases other than skin cancer were also excluded from the subcohort, in which 1716 women remained.

\section{Socioeconomic Status}

Socioeconomic status was measured by means of highest level of education attained and occupational history, two of the recommended measures for SES. ${ }^{20}$ Educational level was classified as primary school, lower vocational school (e.g. technical, domestic science school), junior high school, senior high school, higher vocational school, university and other education. Information was available on the highest level of education for the individual and for her partner. Information about occupational history was coded according to a coding system of the Central Bureau of Statistics (CBS) frequently used in the Netherlands. ${ }^{21}$ For the present analysis, these CBS codes were aggregated according to occupational sector and training required (EGP) and according to social standing (U\&S). The EGP coding scheme is a reconstruction of the scheme developed by Erikson et al. ${ }^{22}$ This coding scheme is based on four facets of occupation: occupational group, required training, self-support/independence and leadership. Each occupation is classified into 10 categories according to these aspects. ${ }^{23}$ This list has been adapted for the Netherlands and is still comparable with the original list. ${ }^{24}$ The U\&S score is also comparable with international classifications. ${ }^{23}$ The construction of this list was based on the ranking of 116 occupational titles by 500 respondents according to social standing. ${ }^{23}$ Other factors relevant to the association between SES and breast cancer risk that were measured included benign breast disease, familial breast cancer, parity, age at first birth, age at menarche, age at menopause, oral contraceptive use, current cigarette smoking, Quetelet index $\left(\mathrm{kg} / \mathrm{m}^{2}\right)$ and alcohol intake. In the cohort study the association between dietary fat and breast cancer risk has been studied previously ${ }^{19}$ and since no association was found, we did not include fat intake in our analyses.

\section{Data Analysis}

The distribution of SES indicators was compared in the case and subcohort groups. Educational level was aggregated into five categories: primary school, lower vocational school, junior high school, senior high school and higher vocational school or university. The EGP score of the last occupation was divided into four categories: upper white-collar jobs (professionals and managers), lower white-collar jobs (non-manual workers), blue-collar jobs (manual workers) and others (farmers, self-employed people and housewives). The U\&S score (also based on last occupation) was divided into five categories ranging from low (e.g. cleaner) to high social standing (e.g. teacher). An extra category was added for housewives and included women who had never had paid employment. The associations between SES and covariates were also studied in the subcohort, by comparing mean values of age, parity, age at first birth, age at menarche, age at menopause, alcohol consumption and Quetelet index and comparing the prevalence of benign breast disease, familial breast cancer, smoking and oral contraceptive use in relevant SES categories.

To study the association between SES and breast cancer risk and the role of potential risk factors mentioned above, data were analysed using the casecohort approach. ${ }^{19,25}$ Mantel-Haenszel rate ratios of breast cancer were determined for each of the SES indicators, stratified for age. In the multivariate casecohort analyses, using the GLIM statistical package, ${ }^{26}$ rate ratios and $95 \%$ confidence intervals $(\mathrm{CI})$ of breast cancer were computed for the four SES indicators, after adjustment for the covariates mentioned above.

\section{RESULTS}

The distribution of SES indicators in the cases and in the subcohort is presented in Table 1. Cases had a somewhat lower level of education than subcohort members, but this difference was very small. The same pattern is seen when the highest level of education in the household is compared between cases and the subcohort. Cases more often had a white-collar occupation but there was no appreciable difference in the distribution among the social standing categories. The results of the age-stratified analysis of traditional risk factors for breast cancer in the cohort study have been reported previously. ${ }^{19}$ Briefly, women with benign breast disease had a higher risk for breast cancer 
TABLE 1 Distribution of socioeconomic status indicators in breast cancer cases and subcohor

\begin{tabular}{|c|c|c|c|c|}
\hline \multirow[t]{2}{*}{ Characteristic } & \multicolumn{2}{|c|}{ Subcohort } & \multicolumn{2}{|c|}{ Cases } \\
\hline & No. & $\%$ & No. & $\%$ \\
\hline Total & 1716 & & 471 & \\
\hline \multicolumn{5}{|l|}{ Highest level of education } \\
\hline primary school & 603 & 35.8 & 172 & 37.1 \\
\hline lower vocational & 384 & 22.8 & 109 & 23.5 \\
\hline junior high school & 476 & 28.2 & 120 & 25.9 \\
\hline senior high school & 86 & 5.1 & 26 & 5.6 \\
\hline higher vocational/university & 137 & 8.1 & 37 & 8.0 \\
\hline \multicolumn{5}{|c|}{ Highest level of education (household) } \\
\hline primary school & 371 & 22.0 & 108 & 23.3 \\
\hline lower vocational & 350 & 20.7 & 107 & 23.1 \\
\hline junior high school & 517 & 30.6 & 127 & 27.4 \\
\hline senior high school & 132 & 7.8 & 43 & 9.3 \\
\hline higher vocational/university & 320 & 18.9 & 79 & 17.0 \\
\hline \multicolumn{5}{|l|}{ EGP score:" last profession } \\
\hline blue-collar & 457 & 32.8 & 128 & 31.9 \\
\hline lower white-coliar & 350 & 25.1 & 111 & 27.7 \\
\hline upper white-collar & 212 & 15.2 & 70 & 17.5 \\
\hline other & 376 & 27.0 & 92 & 22.9 \\
\hline \multicolumn{5}{|l|}{ U\&S score: last profession } \\
\hline 1 (Jowest) & 449 & 32.2 & 130 & 32.4 \\
\hline 2 & 215 & 15.4 & 61 & 15.2 \\
\hline 3 & 444 & 31.8 & 144 & 35.9 \\
\hline 4 & 79 & 5.7 & 22 & 5.5 \\
\hline 5 (highest) & 19 & 1.4 & 4 & 1.0 \\
\hline 6 housewife & 189 & 13.5 & 40 & 10.0 \\
\hline
\end{tabular}

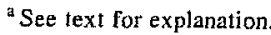

compared with women without benign breast disease. Maternal breast cancer and breast cancer in sisters was also associated with a higher relative risk. Age at first birth and age at menopause were positively associated with breast cancer risk, whereas parity and age at menarche were negatively associated. No associations were found between breast cancer risk and artificial menopause, use of oral contraceptives, current cigarette smoking and Quetelet index.

Table 2 shows the associations between relevant covariates and three SES indicators in the subcohort. The relation between covariates and highest level of education in the household (not presented) is comparable to the relation between covariates and highest level of education of the individual. Women with a higher SES had on average fewer children, a later age at first birth, an earlier age at menarche, a later age at menopause and a higher mean alcohol intake. The mean Quetelet index was higher for women in the lower SES groups. Benign breast disease was more prevalent for women in the highest SES groups, as was the use of oral contraceptives and the percentage ever smoking. The prevalence of breast cancer in sisters was higher in the lowest SES groups, whereas the prevalence of maternal breast cancer was highest in the group with the highest level of education and almost equal in the occupational groups.

The results of the stratified analyses are presented in Table 3. After stratification for age in three 5-year

TABLE 2 Association between possible confounders and socioeconomic status indicators in the subcohort

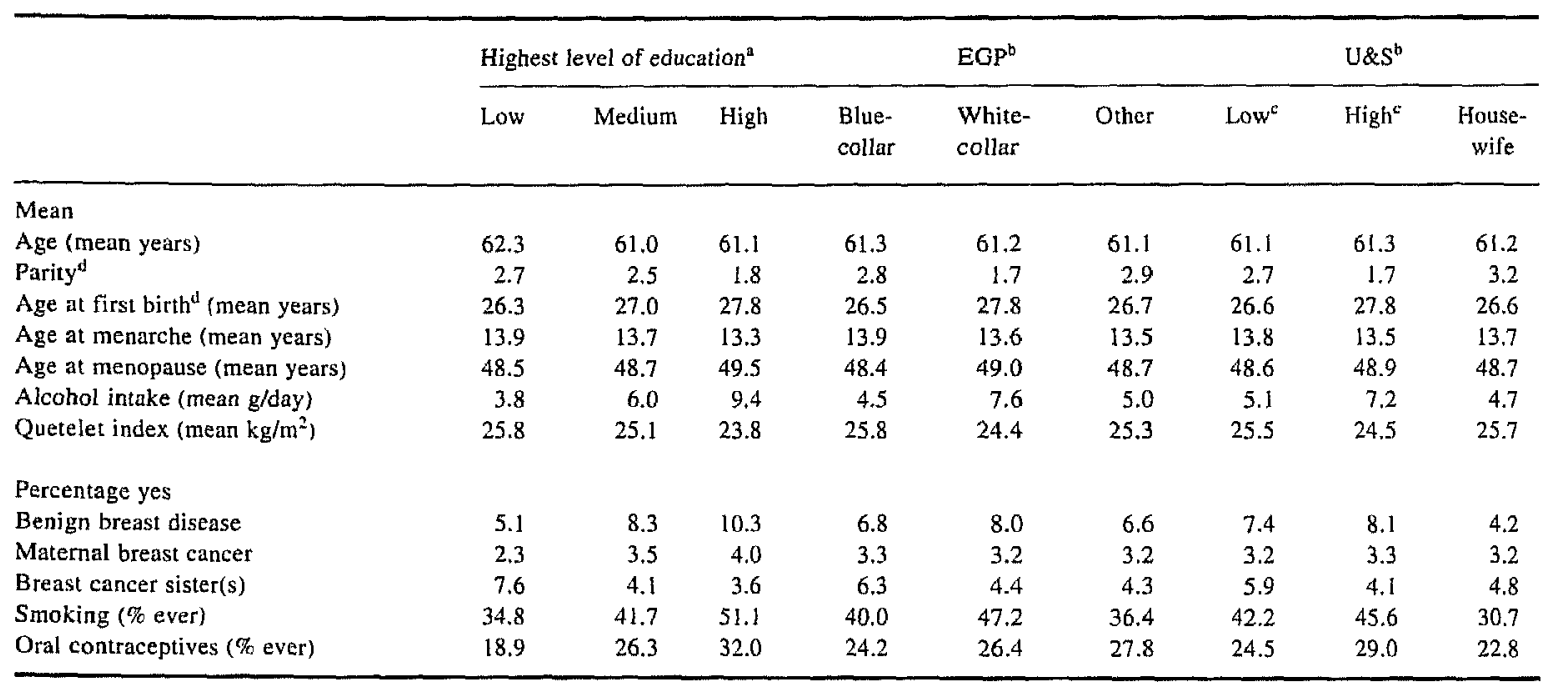

${ }^{a}$ Highest level of education: low = primary school; medium = lower vocational or junior high school; high = senior high school, higher vocational or university.

bee text for explanation.

Low social standing U\&S categories 1 and 2; high social standing U\&S categories 3, 4 and 5.

${ }^{\mathrm{d}}$ For parous women only. 
TABLE 3 Mantel-Haenszel rate ratios for breast cancer according to four different socioeconomic status indicators, adjusted for age

\begin{tabular}{|c|c|c|c|c|c|}
\hline SES indicator & $\begin{array}{c}\text { No, of cases } \\
\text { in cohort }\end{array}$ & $\begin{array}{l}\text { Person-years } \\
\text { in subcohort }\end{array}$ & $\mathrm{RR}_{\mathrm{MH}}$ & $\begin{array}{l}95 \% \text { confidence } \\
\text { interval }\end{array}$ & $\begin{array}{c}\chi^{2} \text { test for trend } \\
(P \text {-value })\end{array}$ \\
\hline \multicolumn{6}{|l|}{ Highest level of education } \\
\hline $\begin{array}{l}\text { primary school } \\
\text { lower vocational }\end{array}$ & $\begin{array}{l}172 \\
109\end{array}$ & $\begin{array}{l}1951 \\
1240\end{array}$ & 1.05 & $0.79-1.39$ & $0.15(0.70)$ \\
\hline $\begin{array}{l}\text { lower vocational } \\
\text { junior high school }\end{array}$ & 120 & 1548 & 0.90 & $0.69-1.17$ & \\
\hline senior high school & 26 & 276 & 1.08 & $0.67-1.73$ & \\
\hline higher vocational/university & 37 & 450 & 0.94 & $0.63-1.39$ & \\
\hline \multicolumn{6}{|c|}{ Highest level of education (household) } \\
\hline primary school & 108 & 1194 & $1^{a}$ & & \\
\hline lower vocational & 107 & 1135 & 1.08 & $0.79-1.48$ & $0.98(0.32)$ \\
\hline junior high school & 127 & 1688 & 0.85 & $0.63-1.14$ & \\
\hline senior high school & 43 & 420 & 1.12 & $0.74-1.69$ & \\
\hline higher vocational/university & 79 & 1041 & 0.83 & $0.60-1.16$ & \\
\hline \multicolumn{6}{|l|}{ EGP score: ${ }^{b}$ Jast profession } \\
\hline blue-collar & 128 & 1477 & $1^{\mathbf{a}}$ & & \\
\hline lower white-collar & 111 & 1136 & 1.12 & $0.84-1.50$ & $0.91(0.34)$ \\
\hline upper white-collar & 70 & 697 & 1.16 & $0.83-1.62$ & \\
\hline other ${ }^{2}$ & 92 & 1213 & 0.87 & $0.64-1.18$ & \\
\hline \multicolumn{6}{|l|}{ U\&S score: ${ }^{b}$ last profession } \\
\hline 1 (lowest) & 130 & 1454 & $1^{\mathrm{a}}$ & & \\
\hline 2 & 61 & 699 & 0.96 & $0.68-1.36$ & \\
\hline 3 & 144 & 1444 & 1.10 & $0.84-1.44$ & $0.03(0.86)$ \\
\hline 4 & 22 & 260 & 0.95 & $0.57-1.58$ & \\
\hline 5 (highest) & 4 & 62 & 0.73 & $0.24-2.23$ & \\
\hline housewife ${ }^{\mathrm{c}}$ & 40 & 603 & 0.73 & $0.49-1.08$ & \\
\hline
\end{tabular}

a Reference category.

bee text for explanation.

Excluded from test for trend.

categories there was no association between the highest level of education and breast cancer risk (RR highest/ lowest $=0.94,95 \% \mathrm{CI}: 0.63-1.39$, trend $P=0.70$ ). Upper white-collar workers had a higher breast cancer rate compared to blue-collar workers ( $R R=1.16,95 \%$ CI : 0.83-1.62) with intermediate values for lower white-collar workers (trend- $P=0.34$ ). Women with a higher social standing job had a non-significantly lower rate of breast cancer than women with a lower U\&S score $(\mathrm{RR}=0.73,95 \% \mathrm{Cl}: 0.24-2.23$ ).

After further adjustment for the covariates (Table 4), there are only slight changes in the relation between highest level of education and breast cancer risk (trend$P=0.45$ ). The breast cancer rate of lower white-collar workers became comparable to the rate of blue-collar workers ( $\mathrm{RR}=1.01,95 \% \mathrm{CI}: 0.69-1.49$ ), whereas upper white-collar workers still had a somewhat higher breast cancer rate ( $R R=1.19,95 \% \mathrm{CI}: 0.80-1.76)$. The association between social standing and breast cancer changed a little: the breast cancer rate ratio in the middle U\&S groups was somewhat higher, but rate ratios for breast cancer in the highest U\&S groups were still below one.
We have also conducted analyses with the two highest categories of U\&S score combined and this did not alter the results. The same applies to level of education.

\section{DISCUSSION}

We did not find a higher risk of breast cancer for those with higher SES. The EGP score of the last profession showed a weak association, with the highest risk for upper white-collar workers, who had a $19 \%$ higher risk for breast cancer compared with blue-collar workers. This is not considered to be a large increase. Besides, the trend test did not show significance nor were the relative rates in the different categories statistically significantly different from one. Neither highest level of education nor U\&S score had a positive association with breast cancer. Adjustment for known risk factors for breast cancer that were associated with SES did not alter the association between SES and breast cancer risk. 
TABLE 4 Rate ratio for breast cancer according to four different socioeconomic status indicators in multivariate analysis

\begin{tabular}{|c|c|c|c|}
\hline \multicolumn{4}{|l|}{ Highest level of education } \\
\hline lower vocational & 1.07 & $0.77-1.49$ & $0.60(0.45)$ \\
\hline junior high school & 0.88 & $0.63-1.21$ & \\
\hline senior high school & 1.14 & $0.66-1.97$ & \\
\hline \multicolumn{4}{|c|}{ Highest level of education (household) } \\
\hline primary school & $1^{\mathbf{b}}$ & & \\
\hline lower vocational & 1.06 & $0.72-1.56$ & $0.96(0.33)$ \\
\hline junior high school & 0.87 & $0.61-1.26$ & \\
\hline senior high school & 1.31 & $0.81-2.13$ & \\
\hline higher vocational/university & 0.81 & $0.52-1.26$ & \\
\hline other ${ }^{d}$ & 0.95 & $0.66-1.36$ & \\
\hline \multicolumn{4}{|l|}{ U\&S score: ${ }^{c}$ last profession } \\
\hline 1 (lowest) & $1^{b}$ & & \\
\hline 2 & 1.06 & $0.71-1.59$ & \\
\hline 3 & 1.23 & $0.89-1.70$ & $0.41(0.52)$ \\
\hline 4 & 0.95 & $0.53-1.70$ & \\
\hline 5 (highest) & 0.76 & $0.24-2.40$ & \\
\hline housewife $\mathrm{d}^{\mathrm{d}}$ & 0.76 & $0.45-1.31$ & \\
\hline
\end{tabular}

a Relative rate after adjustment for age, benign breast disease, maternal breast cancer, breast cancer in sister(s), age at first birth, parity, age at menarche, age at menopause, oral contraceptive use, Quetelet index, alcohol use, current cigarette smoking.

${ }^{b}$ Reference category

- See text for explanation.

dExcluded from test for trend.

This cohort study was conducted in a large sample of the general population of women aged 55-69 years at baseline. After the follow-up period of 3.3 years, 471 breast cancer cases were detected. This is considered to be a sufficient number to find significant associations when risk factors have a near normal distribution. ${ }^{27}$ Most of the women had attended primary school, lower vocational school or junior high school, and a substantial number had attained higher educational levels resulting in a distribution of subjects over the SES categories which was not optimal but still made it possible to study the association with breast cancer risk. During the follow-up period of 3.3 years, there was $100 \%$ follow-up of person-years and the completeness of cancer follow-up was also very high, indicating that selection bias due to loss to follow-up is unlikely. Also, there were no reasons to assume that residual confounding was still present, because all known risk factors for breast cancer were measured and controlled for in the multivariate analyses.

Another fact that could have influenced the results is misclassification of exposure. Socioeconomic status is operationalized as highest level of education, EGP score (functional level) and U\&S score (social standing), both based on the last occupation. Highest level of education is a characteristic that is easily obtainable and recordable, moreover it applies to every adult individual. With the occupation-based SES indicators there is a problem of how to classify the large majority of women with no formal employment. All women were classified according to their last occupation, although almost $50 \%$ of the women finished their formal employment 30 years before, which was typical for the Netherlands. ${ }^{28}$ The SES of the last occupation will therefore have a limited value. It is also possible to classify women according to their husband's occupation. This may lead to misclassification since other studies have indicated that $40 \%$ of the working women in the USA had an occupational status higher than that of their husband. ${ }^{29}$ This difference most often occurs when the husband has a manual blue-collar job and the wife has a sales or clerical white-collar job. ${ }^{30}$ Although this is merely an artefact of the occupational scales, because women in routine non-manual jobs 
seem comparable to men doing manual work with respect to SES, ${ }^{31}$ it seems better to use the highest occupational level in the household. Unfortunately, we had only the occupational history of the woman and not that of her partner. However, we did have information about the highest level of education of the individual and her partner and used them both in the analyses of SES and breast cancer risk: this did not lead to different results.

Detection bias may be another concern in breast cancer studies. In the Netherlands there are no large differences in access to medical care between SES categories and at the start of our cohort study breast cancer screening was not widespread. So, it is unlikely that these factors had an influence on the results. Moreover, we have examined the association between tumour site at time of diagnosis and the three SES indicators within the cohort and we did not find a clear association among the different SES categories (data not shown).

We did not include dietary fat intake into our models, since earlier analyses in the cohort study did not show an association between dietary fat intake and breast cancer. ${ }^{19}$ Besides, subjects in the higher SES categories in general eat more fruit, vegetables and dietary fibre and less fat and energy, ${ }^{32-34}$ indicating that differences in dietary habits between SES categories should rather lead to an inverse association between SES and breast cancer, instead of a positive association.

In 11 studies on SES and breast cancer highest level of education or years of completed schooling were used as an SES indicator. ${ }^{1-11}$ Although almost all reported a positive association between SES and breast cancer, there were differences in significance and magnitude: relative risks of the highest versus the lowest category varied from 1.0 to 2.5 . These differences in results are probably due to differences in the use of control variables, because in almost all studies that included age as the only confounding variable, significant positive associations were found, with relative rates varying from 1.2 to 2.5. This is not comparable with our results, since we did not find a positive association between level of education and breast cancer risk in the age-adjusted analyses.

In two case-control studies ${ }^{4,6}$ the association between breast cancer risk and occupation-based SES indicators was investigated. We could not directly compare our results with these studies, because other reference categories were used, e.g. farmers, ${ }^{4}$ housewives or the self-employed. ${ }^{6}$ Both studies reported a higher breast cancer risk among white-collar workers compared with blue-collar workers, after adjustment for education and marital status ${ }^{4}$ or age, parity and place of residence. ${ }^{6}$ Only one cohort study used a subject's occupation as
SES indicator and no regular pattern between occupation and breast cancer risk was reported. ${ }^{11}$ In another cohort study the occupation of the head of household was used as an indicator of SES ${ }^{9}$ and a third cohort study was restricted to economically active women at baseline; ${ }^{12}$ in these two studies significant positive associations were reported between SES and breast cancer risk. Therefore, various SES indicators (years of education, educational level, own occupation or highest occupation in the household) showed positive associations with breast cancer risk, indicating that differences in SES indicators between our study and the reviewed studies are not responsible for discrepancies in results. All the risk factors for breast cancer we have studied except breast cancer in sister(s) and a higher Quetelet index, were more prevalent in the highest SES groups, suggesting that women in the highest SES groups might have a higher unadjusted breast cancer risk. However, some of the differences were modest and the relative risks associated with these factors are mostly modest as well. ${ }^{19}$ It is therefore possible that differences in the distribution of these risk factors are not big enough to cause differences in breast cancer risk between SES groups. While it is possible that confounding by traditional breast cancer risk factors can explain part of the association in other published studies, the fact that we did not find a positive association with SES is comparable with the finding that differences in self-reported health between SES categories are smaller for women in the Netherlands compared to differences in most other European countries and North America. ${ }^{35}$ This may be a result of relatively small inequalities in level of education and income in the Netherlands and the social security and welfare system.

In conclusion, we found no association between breast cancer risk and various indicators of SES. This is not in agreement with studies conducted in other European countries and North America, which often report weak associations between SES and breast cancer. While confounding by traditional risk factors for breast cancer may explain part of the positive associations reported in other studies, the fact that we did not find a positive association between SES and breast cancer is comparable with the finding that health differences between SES categories are smaller in the Netherlands than in most other European countries and North America.

\section{ACKNOWLEDGEMENTS}

We want to thank the participants in this study, the regional cancer registries (IKA, IKL, IKMN, IKN, 
IKO, IKR, IKST, IKW, IKZ), PALGA for providing incidence data; E Dorant, S van de Crommert, H Brants, $P$ Florax, J Nelissen and $W$ van Dijk for assistance in the cohort study and $S$ van den Heuvel from the TNO-NIPG institute for coding the questions about occupation.

This work was financially supported by the Dutch Ministry of Welfare, Public Health and Cultural Affairs and by the Dutch Cancer Society.

\section{REFERENCES}

' Baquet C R, Horm J W, Gibbs T, Greenwald P. Socioeconomic factors and cancer incidence among blacks and whites. $J$ Natl Cancer Inst 1991; 83: 551-57.

${ }^{2}$ Williams R R, Horm J W. Association of cancer sites with tobacco and alcohol consumption and socioeconomic status of patients: interview study from the third national cancer survey. J Natl Cancer Inst 1977; 58: 525-47.

${ }^{3}$ Harris R E, Wynder E L. Breast cancer and alcohol consumption. A study in weak associations. JAMA 1988; 259: 2867-71.

${ }^{4}$ Talamini R, La Vecchia C, Decarli A et al. Social factors, diet and breast cancer in a northern Italian population. $\mathrm{Br} J$ Cancer 1984; 49: 723-29.

${ }^{5}$ Marubini E, Decarli A, Costa A et al. The relationship of dietary intake and serum levels of retinol and beta-carotene with breast cancer. Results of a case-control study. Cancer 1988; 61: 173-80.

${ }^{6}$ Ewertz M. Risk of breast cancer in relation to social factors in Denmark. Acta Oncol 1988: 27: 787-92.

${ }^{7}$ Harris R E, Zang E A, Wynder E L. Oral contraceptives and breast cancer risk: a case-control study. Int $J$ Epidemiol 1990; 19: $240-46$.

${ }^{8}$ Van 't Veer P, Dekker J M, Lamers J W L et al. Consumption of fermented milk products and breast cancer: a case-control study in the Netherlands. Cancer Res 1989; 49:4020-23.

${ }^{9}$ Rimpela A H, Pukkala E I. Cancers of affluence: positive social class gradient and rising incidence trend in some cancer forms. Soc Sci Med 1987; 24; 601-06.

${ }^{10}$ Carter C L, Jones D Y, Schatzkin A, Brinton L A. A prospective study of reproductive, familial and socioeconomic breast cancer using the NHANES I data. Public Health Rep 1989; 104: $45-50$.

"Leon D A. Longitudinal Study: Social Distribution of Cancer, 1971-1975. (OPC Series LS No. 3). London: HMSO, 1988.

12 Vågerö D, Persson G. Occurrence of cancer in socioeconomic groups in Sweden. Scand J Soc Med 1986; 14: 151-60.

${ }^{13}$ Ewertz M, Duffy S W, Adami H-O et al. Age at first birth, parity and risk of breast cancer: A meta-analysis of 8 studies from the Nordic countries. Int J Cancer 1990; 46: 597-603.

${ }^{14}$ Graham S, Hellman R, Marshall $J$ et al. Nutritional epidemiology of postmenopausal breast cancer in Western New York. Am J Epidemiol 1991: 134: 552-66.

${ }^{15}$ Kelsey J L, Gammon M D. Epidemiology of breast cancer. Epidentiol Rev 1990; 12: 228-40.

${ }^{16}$ Jacobsen B K, Lund E. Level of education, use of oral contraceptives and reproductive factors: The Trömsö Study. Int J Epidemiol 1990; 19: 967-70.

${ }^{17}$ Van den Brandt P A, Goldbohm R A, Van 't Veer P, Volovics $A$, Hermus $R J J$, Sturmans $F$. A large-scale prospective cohort study on diet and cancer in the Netherlands. $J$ Clin Epidemiol 1990; 43: 285-95.

${ }^{18}$ Van den Brandt P A, Schouten L J, Goldbohm R A, Dorant E, Hunen $P$ M H. Development of a record linkage protocol for use in the Dutch cancer registry for epidemiological research. Int J Epidemiol 1990; 19: 553-58.

${ }^{19}$ Van den Brandt P A, Van 't Veer P, Goldbohm R A $t$ t al. A prospective cohort study on dietary fat and the risk of postmenopausal breast cancer. Cancer Res 1993; 53: $75-82$.

${ }^{20}$ Liberatos P, Link B G, Kelsey J L. The measurement of social class in epidemiology, Epidemiol Rev 1988; 10: 87-121,

${ }^{21}$ Centraal Bureau voor de Statistiek. Beroepenclassificatie 1984. Lijst van Benamingen per Beroepencode. Voorburg: CBS, 1985.

${ }^{22}$ Erikson R, Goldthorpe J H, Portocarero L. Intergenerational class mobility in three western countries: England, France and Sweden. Br J Sociol 1979; 30: 425-41.

${ }^{23}$ Van Berkel-van Schaik A B, Tax B. Naar een Standaardoperatonalisatie van Sociaal-Economische Status voor Epidemiologisch en Sociaal-Medisch Onderzoek. SociaalEconomische Gezondheidsverschillen nr. 6. Den Haag, 1990.

${ }^{24}$ Ganzeboom $H$, Luykx R, Dessens J et al. Intergenerationele kJassenmobiliteit in Nederland tussen 1970 en 1985. Mens en Maarschappij 1987; 62: 17-43.

${ }^{25}$ Self S G, Prentice R L. Asymptotic distribution theory and efficiency results for case-cohort studies. Ann Stat 1988; 16: 64-81.

${ }^{26}$ Baker R J. GLIM 3.77 Reference Manual. Oxford: Numerical Algorithms Group, 1985.

${ }^{27}$ Philips A N, Pocock S J. Sample size requirements for prospective studies, with examples for coronary heart disease. J Clin Epidemiol 1989; 42: 639-48.

${ }^{28}$ Hooghiemstra B T J, Niphuis-Nell M. Sociale Atlas van de Vrouw. Deel 2. Arbeid, Inkomen en Faciliteiten om Werken en de Zorg voor Kinderen te Combineren. Den Haag: VUGA, 1993.

${ }^{29}$ Haug M R. Social class measurement and women's occupational roles. Social Forces 1973; 52: 86-98.

${ }^{30}$ Stanworth M. Women and class analysis: A reply to John Goldthorpe. Sociology $1984 ; 18: 159-70$

${ }^{31}$ Goldthorpe J H. Women and class analysis: In defence of the conventional view. Sociology $1983 ; 17: 465-88$.

${ }^{32}$ Hulshof K F A M, Löwik M R H, Kok F J, Wedel M, Kistemaker C, Brants H A M. Invloed van sociaal-economische status op voeding en anderc leefstijlfactoren. In: Mackenbach J P (ed.). Sociaal-Economische Gezondheidsverschillen Onderzocht, III. Den Haag: DOP, 1991.

${ }^{33}$ Patterson B H, Block G. Food choices and the cancer guidelines. Am J Public Health 1988; 78; 282-86.

${ }^{34}$ Baghurst K I, Record S J, Baghurst P A, Syrette J A, Crawford D, Worsley A. Sociodemographic determinants in Australia of the intake of food and nutrients implicated in cancer aetiology. Med J Aust 1990; 153: 444-52.

${ }^{35}$ Kunst A. E, Geurts J J M, Van den Berg J. International variation in socio-economic inequalities in self-reported health. In: Mackenbach I P (ed.). Sociaal-Economische Gezondheidsverschillen Onderzocht, V. Den Haag: DOP, 1993.

(Revised version received March 1994) 